\title{
Mapping of common bunt resistance gene Bt9 in wheat
}

\author{
Philipp Matthias Steffan ${ }^{1,2} \cdot$ Anna Maria Torp ${ }^{1}$ Anders Borgen ${ }^{1,4} \cdot$ Gunter Backes $^{1,3}$ • \\ Søren K. Rasmussen ${ }^{1}$ (I)
}

Received: 28 October 2016 / Accepted: 26 January 2017 / Published online: 25 February 2017

(c) The Author(s) 2017. This article is published with open access at Springerlink.com

\begin{abstract}
Key message The $B t 9$ resistance locus was mapped and shown to be distinct from the $B t 10$ locus. New markers linked to $B t 9$ have been identified and may be used to breed for resistance towards the seed-borne disease.

Abstract Increasing organic wheat production in Denmark, and in other wheat-producing areas, in conjunction with legal requirements for organic seed production, may potentially lead to a rise in common bunt occurrence. As systemic pesticides are not used in organic farming, organic wheat production systems may benefit from genetic resistances. However, little is known about the underlying genetic mechanisms and locations of the resistance factors for common bunt resistance in wheat. A double haploid (DH) population segregating for common bunt resistance was used to identify the chromosomal location of common
\end{abstract}

Communicated by Mark E. Sorrells.

Electronic supplementary material The online version of this article (doi:10.1007/s00122-017-2868-6) contains supplementary material, which is available to authorised users.

Søren K. Rasmussen

skr@plen.ku.dk

1 Department of Plant and Environmental Sciences, University of Copenhagen, Thorvaldsensvej 40, 1871 Frederiksberg, Denmark

2 Present Address: KWS LOCHOW GMBH, Ferdinand-von-Lochow-Straße 5, 29303 Mons, Germany

3 Present Address: Department of Organic Agricultural Sciences, University of Kassel, Nordbahnhofstraße 1a, 37213 Witzenhausen, Germany

4 Present Address: Agrologica, Houvej 55, 9550 Mariager, Denmark bunt resistance gene $B t 9$. DH lines were phenotyped in three environments and genotyped with DArTseq and SSR markers. The total length of the resulting linkage map was $2882 \mathrm{cM}$ distributed across all 21 wheat chromosomes. Bt9 was mapped to the distal end of chromosome 6DL. Since wheat common bunt resistance gene $B t 10$ is also located on chromosome $6 \mathrm{D}$, the possibility of their co-location was investigated. A comparison of marker sequences linked to $B t 9$ and $B t 10$ on physical maps of chromosome $6 \mathrm{D}$ confirmed that $B t 9$ and $B t 10$ are two distinct resistance factors located at the distal (6DL) and proximal (6DS) end, respectively, of chromosome 6D. Five new SSR markers Xgpw4005-1, Xgpw7433, Xwmc773, Xgpw7303 and Xgpw362 and many SNP and PAV markers flanking the $B t 9$ resistance locus were identified and they may be used in the future for marker-assisted selection.

\section{Introduction}

Although common bunt [caused by Tilletia caries (DC.) Tul. \& C. Tul (syn. T. tritici (Bjerk.) G. Winter in Rabenh.) and T. foetida (Wallr.) Liro (syn. T. laevis Kühn in Rabenh.)] is a major disease in wheat (Triticum aestivum L. subsp. aestivum; van Slageren 1994) worldwide, it has received surprisingly little attention in the last 50 years. The ease of control of common bunt infection in wheat by the application of seed treatments with systemic fungicides (based on hexachlorobenzene, carboxin, difenoconazole or tebuconazole; Hoffmann and Waldher 1981) might be one reason for the lack of research and knowledge about wheat-pathogen (host-common bunt) interactions.

Growing concern about the environmental impact of agricultural production and increased organic wheat production (Eurostat 2014) demands a search for alternative 
modes of control. Furthermore, in many parts of the world, farmers lack access to fungicides, and common bunt has been a continuous threat to wheat production (e.g. Mamluk 1998). The use of host resistance genes in wheat breeding offers a mode of control of common bunt infection.

Sixteen resistance genes, designated Bt1-Bt15 and Btp, have been identified (Goates 2012) and further resistance sources among Ukrainian and Russian germplasm (Martynov and Dobrotvorskaya 2003) and gene bank accessions (Goates and Bockelman 2012) have been reported. In addition, introgressions of common bunt resistance factors from rye (Secale cereale, Martynov and Dobrotvorskaya 2003), triticale (Ciuca 2011), barley (Hordeum vulgare, Rubiales et al. 2001), Aegilops glaucum (Martynov and Dobrotvorskaya 2003), Ae. cylindrica (Galaev et al. 2006), Ae. ventricosa (Babayants et al. 2006), Triticum erebuni (Babayants et al. 2006) and Agropyron intermedium (Goates 1996) have been reported.

To the authors' knowledge, the genetic locations of only three Bt genes and 15 quantitative resistance factors (quantitative trait loci, QTL) for common bunt have so far been mapped (Table 1). In addition, locations of the following Bt genes have been suggested: Bt5 (R.J. Metzger and C.W. Scheller, pers. comm, cited in McIntosh et al. 1998) and Bt6 (ref. 1005 in McIntosh et al. 1998, but not

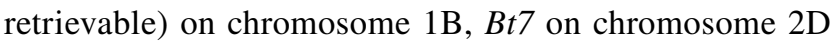

Table 1 Bt genes and QTL for common bunt resistance in wheat for which chromosomal locations are known

\begin{tabular}{|c|c|c|}
\hline Gene & Chromosome & References \\
\hline Bt1 & $2 \mathrm{~B}$ & Sears et al. (1960); Gupta (2007) \\
\hline Bt4 & 1B & Schmidt et al. (1969) \\
\hline Bt10 & $6 \mathrm{DS}$ & Menzies et al. (2006) \\
\hline QCbt.crc-1B.1 & $1 \mathrm{BS}$ & Fofana et al. (2008) \\
\hline QCbt.crc-1B.2 & $1 \mathrm{BL}$ & Fofana et al. (2008) \\
\hline Xgwm $374^{\mathrm{a}}$ & $1 \mathrm{BS}$ & Wang et al. (2009) \\
\hline QCbt.spa-1B & 1B & Singh et al. (2016) \\
\hline$X g w m 273^{\mathrm{a}}$ & 1B & Dumalasová et al. (2012) \\
\hline$Q C b t . s p a-4 B$ & $4 \mathrm{~B}$ & Singh et al. (2016) \\
\hline QCbt.spa-4D & $4 \mathrm{D}$ & Singh et al. (2016) \\
\hline$X g w m 408^{\mathrm{a}}$ & $5 \mathrm{~B}$ & Dumalasová et al. (2012) \\
\hline$Q C b t . s p a-5 B$ & $5 \mathrm{~B}$ & Singh et al. (2016) \\
\hline QCbt.spa-6D & $6 \mathrm{D}$ & Singh et al. (2016) \\
\hline QCbt.crc-7A & 7AL & Fofana et al. (2008) \\
\hline$X p s p 3050^{\mathrm{a}}$ & $7 \mathrm{~A}$ & Dumalasová et al. (2012) \\
\hline$X g w m 43^{\mathrm{a}}$ & $7 \mathrm{~B}$ & Dumalasová et al. (2012) \\
\hline QCbt.spa-7B.1 & $7 \mathrm{~B}$ & Knox et al. (2013) \\
\hline QCbt.spa-7D & $7 \mathrm{D}$ & Singh et al. (2016) \\
\hline
\end{tabular}

${ }^{a}$ For QTLs that were not designated in accordance with McIntosh et al. (1998), the name of the nearest flanking marker is given
(R.J. Metzger, pers. comm, cited in McIntosh et al. 1998), and Bt11 on chromosome 3B (Ciuca 2011). Although Bt8 has not been mapped, it is not located on chromosomes 5A, 1B or 2D (Waud and Metzger 1970).

Tilletia sp. and wheat follow the classic gene-for-gene concept of pathogen-host interactions (Reed 1928; Bressman 1931). It has been shown numerous times that such resistance may easily be overcome by the pathogen (e.g. leaf rust, Long et al. 1998). In fact before the introduction of hexachlorobenzene in 1956 for seed treatment to control common bunt, a resistance breakdown was noticed (Hoffmann 1971). The threshold level for common bunt is very low, because the disease is not only affecting the yield but indeed also affect quality of the grain at a much lower infection level. It is possible that a sum of several additive partial resistances could accumulate to sufficient resistance level, but so far this has not been documented.

Marker-assisted selection in plant breeding offers the possibility to breed lines with more than one resistance source (Kloppers and Pretorius 1997), and thus create host resistance diversity that may be more difficult to overcome by pathogens and provide more durable resistance. However, marker-assisted selection and gene-pyramiding strategies rely on sound genetic understanding of resistance factors.

The early identification of chromosomal locations of resistance factors was achieved by the use of monosomic wheat lines (Sears et al. 1960; Schmidt et al. 1969), while more recently molecular markers have been employed (e.g. Demeke et al. 1996; Laroche et al. 2000; Ciucã 2011; Singh et al. 2016). Marker-assisted selection for common bunt resistance in wheat is, however, only applied for the $B t 10$ resistance gene (Menzies et al. 2006). Common bunt resistance genes $B t 9$ and $B t 10$ were derived from the same cross between common bunt-susceptible $c v$. Elgin and gene bank accession PI 178383, a landrace collected in Turkey (Harlan 1950). From this cross, gene bank accessions PI 554099 and PI 554118 were developed, carrying resistance genes $B t 9$ and $B t 10$, respectively (Goates 1996). Their classification into two distinct resistance factors has so far relied on their different resistance reactions to various common bunt isolates (e.g. Goates 2012) and, to the authors' knowledge, no genetic evidence about their distinctness is available. In order to advance molecular resistance breeding in wheat against common bunt, this study (1) assessed the efficacy of the resistance gene $B t 9$ in Denmark, (2) used the offspring of a cross between PI 554099, carrying Bt9 (Goates 2012), and a common bunt-susceptible cultivar to map the chromosomal location of $B t 9$, and (3) investigated the possible co-location of resistance genes $B t 9$ and Bt10. 


\section{Materials and methods}

\section{Plant material}

A population of 91 double haploid (DH) lines segregating for common bunt resistance gene $B t 9$ was generated (Erik Tybirk, Nordic Seed A/S, Galten, Denmark) from microspores off approximately $15 \mathrm{~F} 1$ plants following a proprietary protocol. The cross was made between wheat accession PI 554099 (National Small Grains Collection, Aberdeen, Idaho, USA), carrying resistance gene $B t 9$, and common bunt susceptible-wheat cv. Cortez (Wiersum Plant Breeding, Winschoten, The Netherlands).

\section{Fungal spores}

Common bunt teliospores were received from Bent J. Nielsen (Aarhus University, Aarhus, Denmark) as a bulk composite from a broad selection of locations in Denmark, representing the virulence spectrum of Danish common bunt isolates. The bulk composite of common bunt spores was maintained by inoculating a broad range of common bunt-susceptible wheat accessions which have been shown not to possess any common bunt resistances. For a specific study against a single gene, in this case $B t 9$, it makes no difference which race is used or if it is a mixture of races, as long as none of the races in a bulk has virulence against the gene in question. It has been documented in our association mapping that the bulk of spores did not contain any virulence against $B t 9$ (Steffan et al., unpublished data; Borgen 2015).

\section{Phenotyping reaction to common bunt}

The DH population was evaluated for common bunt resistance under field conditions in 2012 and 2013 in Mariager $\left(56.39^{\circ} \mathrm{N} 10.01^{\circ} \mathrm{E}\right)$, Denmark, and in 2013 under greenhouse conditions at the experimental farm $\left(55.67^{\circ} \mathrm{N}\right.$; $\left.12.30^{\circ} \mathrm{E}\right)$ in Taastrup, Denmark. The environments were designated Fd12 and Fd13 for the field assessments in 2012 and 2013, respectively, and Gh13 for the greenhouse assessment in 2013. DH lines were assessed in two replications in Fd12 and in one replication in Fd13 and Gh13.

Sowing of field trials Fd12 and Fd13 was performed as follows: $50-80$ seeds of each $\mathrm{DH}$ line per replicate were sown by hand in 1-m rows in the field in mid-October in 2011 and in late October in 2012. Seeds were inoculated with common bunt by mixing and shaking with an abundance of bunt teliospores in a container, and sieved in a mesh allowing spores to pass but retaining the wheat seeds prior to sowing. For the sowing of the greenhouse assessment Gh13, 50 seeds per DH line were sown in plastic containers filled with potting soil in October 2012.
Temperatures were the standard of the greenhouse with 18 and $13{ }^{\circ} \mathrm{C}$ during the day and night, respectively, somewhat higher temperature than recommended (Borgen and Kristensen 2003). From 4 weeks after sowing, plants were vernalised for 8 weeks at $6^{\circ} \mathrm{C}$ in dim light.

\section{Statistical analysis}

Common bunt resistance reaction in DH lines was scored as the percentage of wheat spikes with at least one spikelet with bunt sori relative to total number of spikes. An analysis of variance based on a linear model was used to estimate the effects of genotypes, environments and their interaction on common bunt resistance reactions.

A mixed effects model was used to extract best linear unbiased predictions (BLUPs) for each DH line:

$y_{\mathrm{d}, \mathrm{r}, \mathrm{e}}=\mu+E+(G)+\varepsilon$,

where the common bunt score $y$ of DH line $d$ in replication $r$ in environment $e$ is given by $y_{d, r, e}$ and the overall mean is indicated by $\mu$. The effect of the three environments Fd12, Fd13 and Gh13 is included as a fixed effect $E$, and the genotype effect is included as the random effect $(G)$. The error term is denoted $\varepsilon$.

\section{Genotyping using DNA markers}

DNA extraction was carried out as described in Orabi et al. (2014). Genotyping with DArTseq markers was performed by Triticarte Pty. Ltd (Canberra, Australia). DArTseq is a marker technique built on DNA complexity reduction as described for DArT markers (Akbari et al. 2006), followed by sequencing of the DNA representations on next-generation sequencing platforms. The method generates a high number of SNP (single-nucleotide polymorphism) and PAV (presence and absence variant) markers that can be used for, e.g. genetic mapping (Cruz et al. 2013; Li et al. 2015). To investigate whether $B t 9$ and $B t 10$ co-locate, 41 SSR markers known to span chromosome 6D were selected from genetic and physical maps available at Graingenes (http://wheat.pw.usda.gov/GG3/) and cMAP (https://ccg. murdoch.edu.au/cmap/ccg-live/cgi-bin/cmap/viewer). Out of the 41 SSR primer pairs tested, 20 resulted in the amplification of a total of 29 polymorphic loci that could be mapped in the DH population. Primer sequences and chromosomal location for the polymorphic markers are shown in Supplementary Table S1. PCR amplification of SSR markers was carried out according to Orabi et al. (2014). SSR fragments were analysed by capillary electrophoresis using an AB/Hitachi 3130xl Genetic Analyzer (Thermo Fisher Scientific Inc., MA, USA), and allele sizes were determined using the software GeneMarker v. 1.95 (SoftGenetics LLC, State College, PA, USA). In addition to this, 
the PCR marker FSD_RSA linked to the Bt10 bunt resistance gene (Laroche et al. 2000) was used on the two parent lines of the mapping population to test for the presence/ absence of this gene. Wheat accessions PI 554118 (Bt10) and PI 178383 (Bt8, Bt9, Bt10) were used as positive controls for the Bt10 gene, while PI 209794 (Bt0) was used as the negative control. PCR was carried out in $10 \mu$ reactions containing $1 \times$ Key buffer (VWR International), $0.2 \mu \mathrm{M}$ of each dNTP, $0.25 \mu \mathrm{M}$ of each primer (FSD and RSA), 0.25 U VWR Taq polymerase and $40 \mathrm{ng}$ of wheat DNA. Primer sequences were obtained from Laroche et al. (2000) and are provided in Table S1. PCR reactions were carried out on a Verity PCR machine (Applied Biosystems) under the following conditions: initial denaturation at $94^{\circ} \mathrm{C}$ for $2 \mathrm{~min}$, 35 cycles of $94^{\circ} \mathrm{C}$ for $1 \mathrm{~min}, 44^{\circ} \mathrm{C}$ for $1 \mathrm{~min}$, and $72^{\circ} \mathrm{C}$ for $2 \mathrm{~min}$, followed by a final extension step at $72^{\circ} \mathrm{C}$ for $7 \mathrm{~min}$. PCR products were analysed on a $1.5 \%$ agarose gel $(140 \mathrm{~V}$ for $40 \mathrm{~min}$ ).

\section{Map construction and QTL analysis}

Before further analysis, SNP and PAV markers with more than 5\% heterozygous scores were removed from the dataset. As the DH population was developed from several F1, a total of 2274 co-dominant SNPs and 31 SSR loci were used to check the DH lines for signs of heterogeneity. The vast majority of the DH lines were homozygotic showing heterogeneity for less than $1 \%$ of these loci, while three DH lines were identified with more that 5\% heterozygous scores for co-dominant SNPs and/or signs of heterozygosity in some of the SSR loci and were removed from further analysis. Heterozygous scores for markers with less than $5 \%$ of this type of score were changed to missing. Subsequently markers with a total of more than $10 \%$ missing data points and/or significant distorted segregation $(P<0.001)$ were removed from the dataset. The remaining SNP, PAV and SSR markers were analysed using the bin functionality of the QTL IciMapping program (Meng et al. 2015) to identify redundant markers. During binning, redundant markers were deleted by missing rate leaving those with fewest missing data points as representatives of the bin. The remaining markers were used for grouping and map calculation in JoinMap ${ }^{\circledR}$ 4.1. (Van Ooijen 2006). Grouping was initially carried out at a LOD threshold of 8-12. Evaluation and chromosome assignment of groups were carried out based on information obtained from the wheat DArTseq map described by Li et al. (2015), as well as from a blast search of SNP and PAV sequences against a local database of wheat sequences based on the Triticum_aestivum. IWGSC1+popseq. 31 genome assembly downloaded from Ensemble plants (http://plants.ensembl.org/Triticum_aestivum/Info/Index) in April 2016. Only markers with a unique location, maximum alignment length and not more than 1 mismatch were used during assignment of linkage groups. Linkage maps were calculated using the regression mapping algorithm in JoinMap ${ }^{\circledR} 4.1$ with the Kosambi mapping function for the calculation of map distances.

Inclusive composite interval mapping (ICIM) ( $\mathrm{Li}$ et al. 2007) implemented in the QTL IciMapping software was used to scan linkage groups for QTL. The QTL analysis was carried out for each environment (Fd12, Fd13 and Gh13) separately as well as on BLUPs derived from model (1) as representatives of the genotypic effect of each DH line across the three environments. These BLUPS are designated Bunt-3Env. The significance levels for declaring a QTL significant were obtained as the 99th percentile of the maximum LOD scores derived from 5000 permutations, and were determined to be 4.2, 4.2, 4.5 and 4.0 for Bunt3Env, Fd12, Fd13 and Gh13, respectively. Mapchart 2.3 (Voorrips 2002) and Sigmaplot 13.0 were used to draw figures.

For linkage group(s) with significant QTL, the physical position of relevant SNP and PAV markers was obtained (when available) from a BLAST search against the Triticum_aestivum.IWGSC1+popseq.31 genome assembly hosted at Ensemble plants (http://plants.ensembl.org/Triticum_aestivum/Info/Index). All hits used had an $E$ value better than $1 \mathrm{E}-20$. The sequences and physical location of the SSR markers were obtained from the integrated physical and genetic maps of the wheat D genome (Jia et al. 2013) available at https://ccg.murdoch.edu.au/cmap/ccglive/ and/or from BLAST of the primer sequences against the Triticum_aestivum.IWGSC1+popseq.31 genome assembly. Retrieved sequences were confirmed by searching for the presence of both primer sequences as well as the expected SSR repeat. Sequences of DArT markers used for the comparison of maps were retrieved from the IWGSC survey sequence annotation viewer hosted at https://urgi. versailles.inra.fr/gb2/gbrowse/wheat_survey_sequence_ annotation/. Finally, the genetic map for linkage groups with significant QTL was recalculated using the order on the physical map as fixed order in JoinMap ${ }^{\circledR} 4.1$.

\section{Results}

\section{Common bunt resistance scoring}

Common bunt infection was successful in all three environments Fd12, Fd13 and Gh13. An analysis of variance indicated a significant influence of genotypes, environments and their interaction on common bunt scores (Table 2), explaining 52, 9 and $29 \%$ of the total variation, respectively.

Infection levels of DH lines were similar in Fd12 and Gh13, with average common bunt incidences of 17.2 and $17.0 \%$, while the average incidence was 41.8 in $\mathrm{Fd} 13$ 
Table 2 Analysis of variance of common bunt scores for $88 \mathrm{DH}$ lines tested in three environments

\begin{tabular}{lrrrrr}
\hline Effect & \multicolumn{1}{l}{ DF } & \multicolumn{1}{l}{ SS } & \multicolumn{1}{l}{ MS } & $F$ value & $P$ value \\
\hline Environments & 2 & 39783.1 & 19891.5 & 137.4 & $<0.0001$ \\
DH lines & 87 & 225688.5 & 2594.1 & 17.9 & $<0.0001$ \\
Envir $\times$ DH lines & 152 & 125024.9 & 822.5 & 5.7 & $<0.0001$ \\
Residual & 325 & 47067.3 & & & \\
\hline
\end{tabular}

$D F$ degrees of freedom, $S S$ sum of squares, $M S$ mean sum of squares

(Table 3; Fig. 1). The resistance gene donor, wheat accession PI 554099, did not show any common bunt infection in location Fd12, while an average infestation level of $3.2 \%$ were observed in location Gh13 (Table 3). The number of spikes available in wheat accession PI 554099 was too low to be analysed in Fd13. The susceptible parent $c v$. Cortez showed high incidences of common bunt, with high infection levels of $61.0 \%$ in location Fd12 and $92.3 \%$ in location Fd13, while a markedly lower infection of $6.7 \%$ were observed in location Gh13 (Table 3).

\section{Map construction and QTL analysis}

Genotyping of the DH lines with DArTseq markers yielded 3129 polymorphic SNP markers and 8109 polymorphic PAV markers. The final map calculated using JoinMap ${ }^{\circledR}$ 4.1 consisted of 34 linkage groups, of which all could be assigned to one of the 21 wheat chromosomes based on information from the wheat DArTseq consensus map described by Li et al. (2015) and BLAST against the Triticum_aestivum.IWGSC1+popseq.31 genome assembly (Supplementary Table S2). The number of markers with a unique position on the linkage map was 1734, representing a total of 7039 SNP, PAV and SSR markers when the binned markers were counted. The total length of the resulting linkage map was $2882 \mathrm{cM}$ distributed across all 21 chromosomes of hexaploid wheat.

Using inclusive composite interval mapping, the presence of a single significant QTL for bunt resistance could be identified at the distal end of wheat chromosome 6DL. The QTL was highly significant in both the individual environments Fd12 (LOD 8.0) and Gh13 (LOD 9.2), as well as when the BLUPs (Bunt-Env3, LOD 13.9) were analysed (Table 4). In location Fd13, a QTL was indicated at position $129 \mathrm{cM}$; however, the LOD score (4.0) was not significant at the significance level of 4.5 determined after 5000 permutations (99th percentile). The identified QTL explained between 37.7 and $53.7 \%$ of the variation (Table 4). Even when the LOD threshold were manually set to $\mathrm{LOD}=3.0$, there were no indications of any additional QTLs for bunt resistance in other positions of the genome. Wheat accession PI 554099 contributed the allele reducing common bunt infection in DH lines in all cases (Fig. 2). The position of the QTL differed between Fd12, Gh13 and Bunt3Env, but combining results from the individual analyses suggested that the QTL is most likely positioned somewhere between 124.5 and $132.5 \mathrm{cM}$ on the current map, a region flanked by markers 1022670 and 3022667 (Table 4). Counting the binned markers, a total of 111 SNP, PAV and SSR markers mapped to this interval. These include the SSR markers Xgpw7433, Xwmc773 and Xgpw7303, which all mapped together with $X g p w 4005-1$ at position $127 \mathrm{cM}$ on the current map. On the physical map of wheat, this corresponded to a region from approximately 170.5 to 176.5 $\mathrm{Mbp}$, a region that contains around 270 genes on the current assembly of wheat chromosome 6D.

As expected, amplification of the FSD_RSA marker linked to the Bt10 resistance gene resulted in a $\sim 275 \mathrm{bp}$ long amplification product in the two Bt10 containing accessions PI 554118 (Bt10) and PI 178383 (Bt8, Bt9, $B t 10)$, while no product of the expected length was seen in the negative control PI 209794 (BtO). None of the parents of the mapping population used in the present study showed any sign of the Bt10 amplification product (Fig. 3); therefore, it was not possible to map Bt10 directly in the DH population. However, the two SSR markers Xwmc749 and Xwms469 known to map 19-20 cM below the Bt10 gene (Menzies et al. 2006) mapped to the same bin at position $24.1 \mathrm{cM}$ in this population and located to a physical

Table 3 Range of infection levels, average infection and standard deviation of infection levels in DH lines segregating for common bunt resistance gene Bt9 in individual environments (Fd12, Fd13, Gh13 as well as for the BLUPs calculated across the three environments (Bunt-3Env)

\begin{tabular}{llllllll}
\hline Environment & No. DH lines & No. spikes & Range & Mean & Std dev & PI 554 099 & $c v$. Cortez \\
\hline Bunt-3Env* & 88 & 13,451 & $-18.4-50.5$ & 0 & 17.5 & -14.3 & 11.6 \\
Fd12 & 79 & 4610 & $0-84.7$ & 17.2 & 24.9 & 0 & 61.0 \\
Fd13 & 77 & 1231 & $0-100$ & 41.8 & 33.3 & n.a. & 92.3 \\
Gh13 & 86 & 7610 & $0-88.5$ & 17.0 & 22.6 & 3.2 & 6.7 \\
\hline
\end{tabular}

The last two columns indicate the parental scores

PI 554099 resistance gene donor, $c v$. Cortez susceptible parent

*BLUPs from Model (1) 

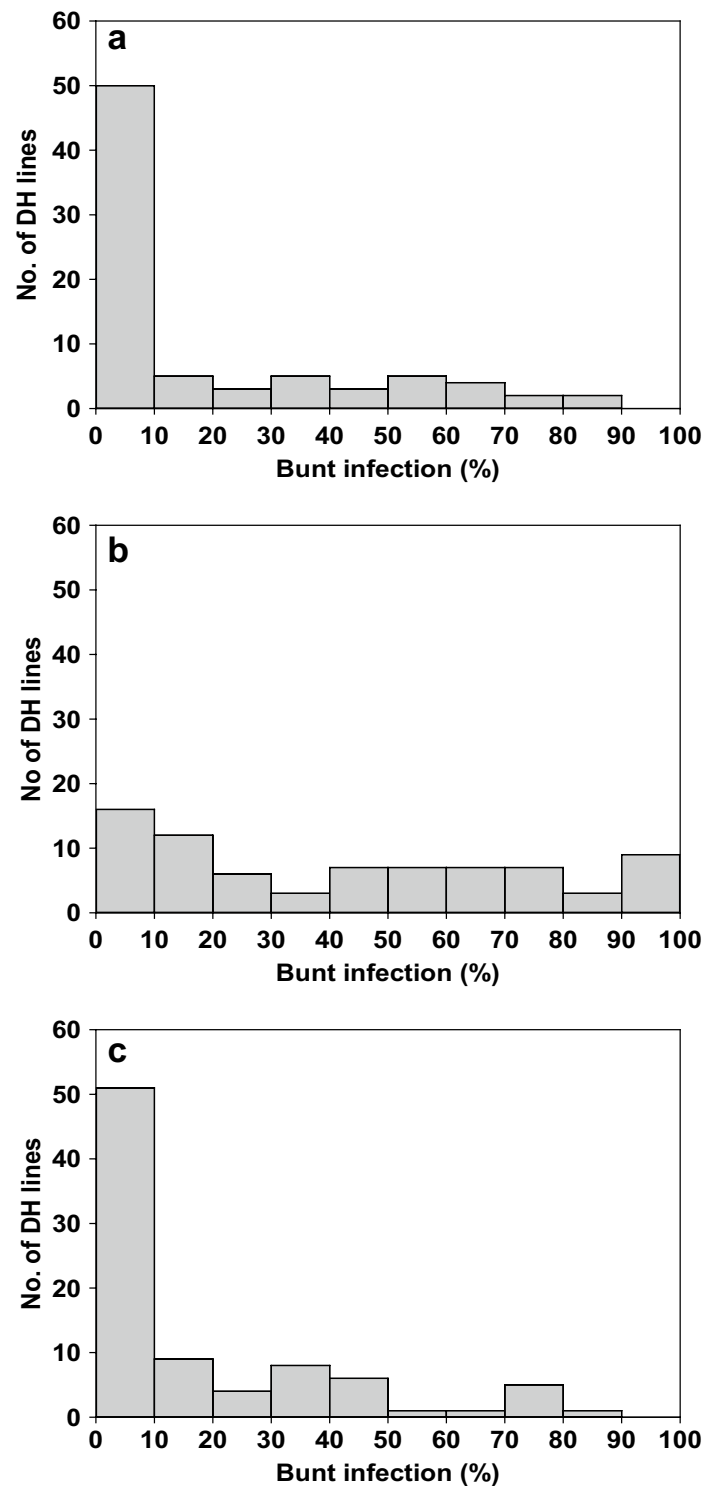

Fig. 1 Common bunt assessment scores in DH lines segregating for common bunt resistance gene $B t 9$ at environments: a Fd12, b Fd13 and $\mathbf{c}$ Gh13. The number of DH lines scored in each environment is given in Table 3

Table 4 QTL for bunt resistance gene $B t 9$ at two different locations Fd12 and Gh13 as well as for BLUPs calculated across the three environments (Bunt-3Env) identified through inclusive composite interval mapping. Flanking markers (Left and Right markers), LOD score, position around 7.2-7.6 Mbp on the wheat genome assembly (Fig. 4). In addition, the DArT markers wPt-741955 and $w P t-2864$ that mapped very close to $Q C b t-s p a-6 D$, probably corresponding to $B t 10$ (Singh et al. 2016), were found to be located at a physical position of approximately 3.9 Mbp. Thus, interpolation between these maps indicates that the Bt10 gene locates to a position in the gap at 5.4 to $21.0 \mathrm{cM}$ between markers 1072489 and $X c f d 75$ on the map developed during this study (Fig. 4).

\section{Discussion}

In this study, common bunt resistance was assessed in wheat DH population in three environments, and by the use of markers a QTL was identified at the distal end of chromosome 6DL explaining a high percentage of the observed phenotype variability, and with a strong allelic substitution effect.

The identification of a single large-effect resistance QTL in the present population was not unexpected since PI 554099 is known to carry the $B t 9$ gene and $c v$ Cortez has been shown to be highly susceptible to common bunt. However, the presence of additional minor effect QTL in the population cannot at present be completely excluded, since the distribution of DArTseq markers was uneven (Table S2), resulting in poor coverage of some chromosomes. The total number of markers was much lower on the D genome (1088) compared to the A (3106) and B (2845) genomes (Table S2), a phenomenon that was also observed by Li et al. (2015) in a mapping study using wheat DArTseq markers. In the case of the present study, however, the shortest linkage groups were observed on chromosomes $6 \mathrm{~B}(48 \mathrm{cM})$ and $7 \mathrm{~B}(73 \mathrm{cM})$. Progress in wheat genome sequencing (Brenchley et al. 2012) and new marker techniques with a better coverage of the wheat genome (Wilkinson et al. 2012) may close the remaining gaps in the nottoo-distant future. The coverage of chromosome 6D, where both the $B t 9$ and $B t 10$ genes for bunt resistance map, was generally good, with a genetic map length of $139 \mathrm{cM}$ and a physical map covering the region from 2.4 to $175.9 \mathrm{Mb}$. The total length of the wheat $6 \mathrm{D}$ assembly is at present

percent variance explained (PVE), allelic substitution effect as well as left (LeftCI) and right (RightCI) borders of the One-LOD drop of confidence interval for the QTL are provided

\begin{tabular}{lllllrlrrr}
\hline Environment & Chromosome & Position $(\mathrm{cM})$ & Left marker & Right marker & LOD & PVE\% & Allelic effect & Left CI & Right CI \\
\hline Bunt-3Env* & 6D & 127 & Xgpw4005-1 & 3024256 & 13.9 & 52.7 & 12.8 & 126.5 & 127.5 \\
Fd12 & 6D & 132 & 1040566 & 3022667 & 8.0 & 37.7 & 15.3 & 129.5 & 132.5 \\
Gh13 & 6D & 125 & 1022670 & 3028756 & 9.2 & 39.9 & 14.3 & 124.5 & 125.5 \\
\hline
\end{tabular}

*BLUPs from Model (1) 

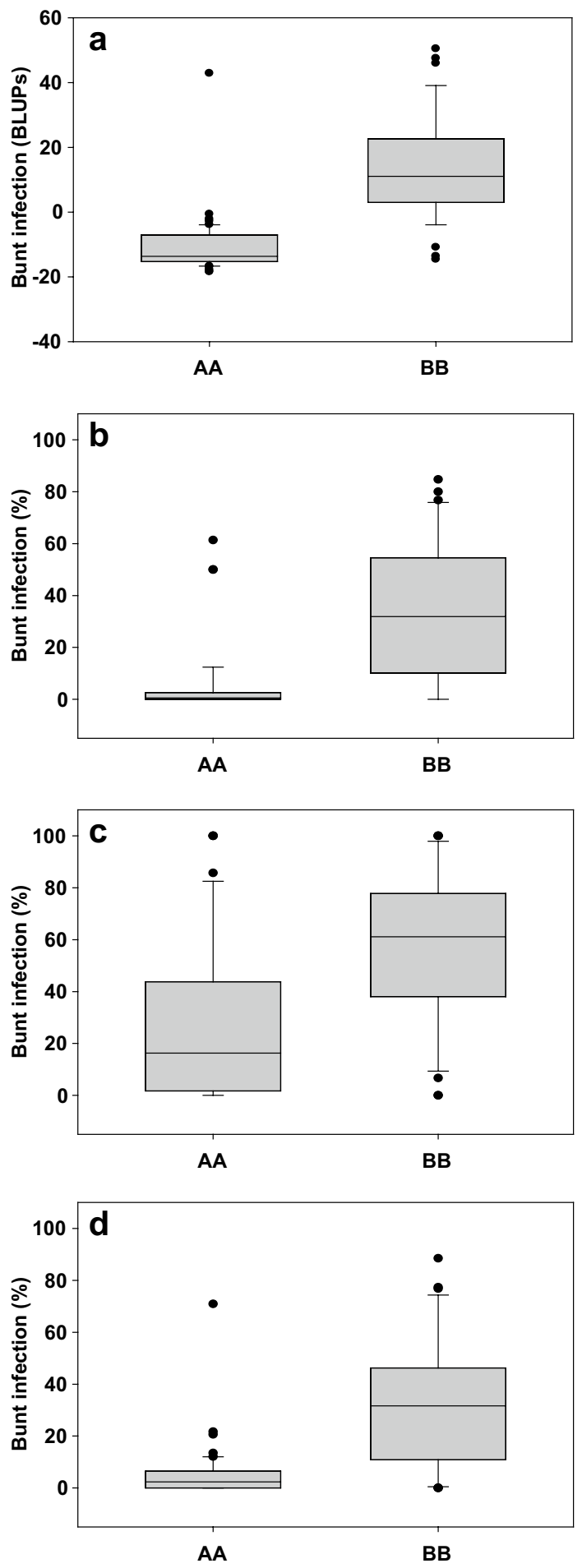

Fig. 2 Allelic substitution effect for SSR marker Xgpw4005-1 linked to $B t 9$ on common bunt resistances for a Bunt-3Env, b Fd12, c Fd13 and d Gh13. $A A$ alleles from resistant parent PI 554099 and $B B$ alleles from susceptible parent $c v$. Cortez

177.0 Mb (http://plants.ensembl.org/Triticum_aestivum/ Info/Index). The large gap in the physical map is likely to span the centromeric region as Xwms 325 has been located



Fig. 3 Agarose gel of BT10 PCR with FSD and RSA primers. Lane identification 1,12=Generuler DNA ladder mix (\#SM0331, Thermo Scientific), 2-3 = PI 554118 (Bt10), 4-5 = PI 178383 (Bt8, Bt9, Bt10), 6-7 = PI $209794(B t 0), 8-9=$ PI554099 (Bt9) and 10-11 = cv Cortez

above the centromere and $\mathrm{XBarc202}$ has been located to bin 6DL1-0.47-0.68 on 6DL (http://wheat.pw.usda.gov/ GG3/). Restricted recombination in centromeric regions has been observed on, e.g. wheat chromosome 3B (Choulet et al. 2014) and is a likely cause of the large gap seen on the physical map here.

To the authors' knowledge, no genetic evidence about the distinctness of bunt resistance genes $B t 9$ and $B t 10$ was available prior to this study. In contrast, in a compressed mixed model association mapping study in which wheat accessions were grouped according to genetic relatedness based on genotyping with DArT markers, wheat accessions PI 178383 (Bt8, Bt9, Bt10), PI 554099 (Bt9) and PI 554118 (Bt10) formed a distinct group within 248 wheat accessions (Steffan et al., unpublished data). However, it is believed that the localisation of $B t 9$ at the distal end of chromosome 6DL and the genetic and physical distance of more than $100 \mathrm{cM}$ and approximately $170 \mathrm{Mb}$, respectively, between $B t 10$ located at the proximal end of chromosome 6DS (Menzies et al. 2006; Singh et al. 2016) and $B t 9$ on the map presented here (Fig. 4) provide strong evidence that $B t 10$ and $B t 9$ are two distinct resistance factors, and confirm the previously used classification based on phenotypic evaluations.

Common bunt resistance gene $B t 9$ was shown to be an effective source of resistance to common bunt in Denmark. No infection was observed in PI 554099 under field conditions neither in this study (2012) nor in another study conducted at the same nursery in Mariager during 2011 and 2012 (Steffan et al., unpublished data, Borgen 2015). However, low levels of infection could be observed in wheat accession PI 554099 under greenhouse conditions during this study. Inconsistent results of common bunt resistance tests under greenhouse conditions have previously been reported (Schmidt et al. 1969). However, since average 


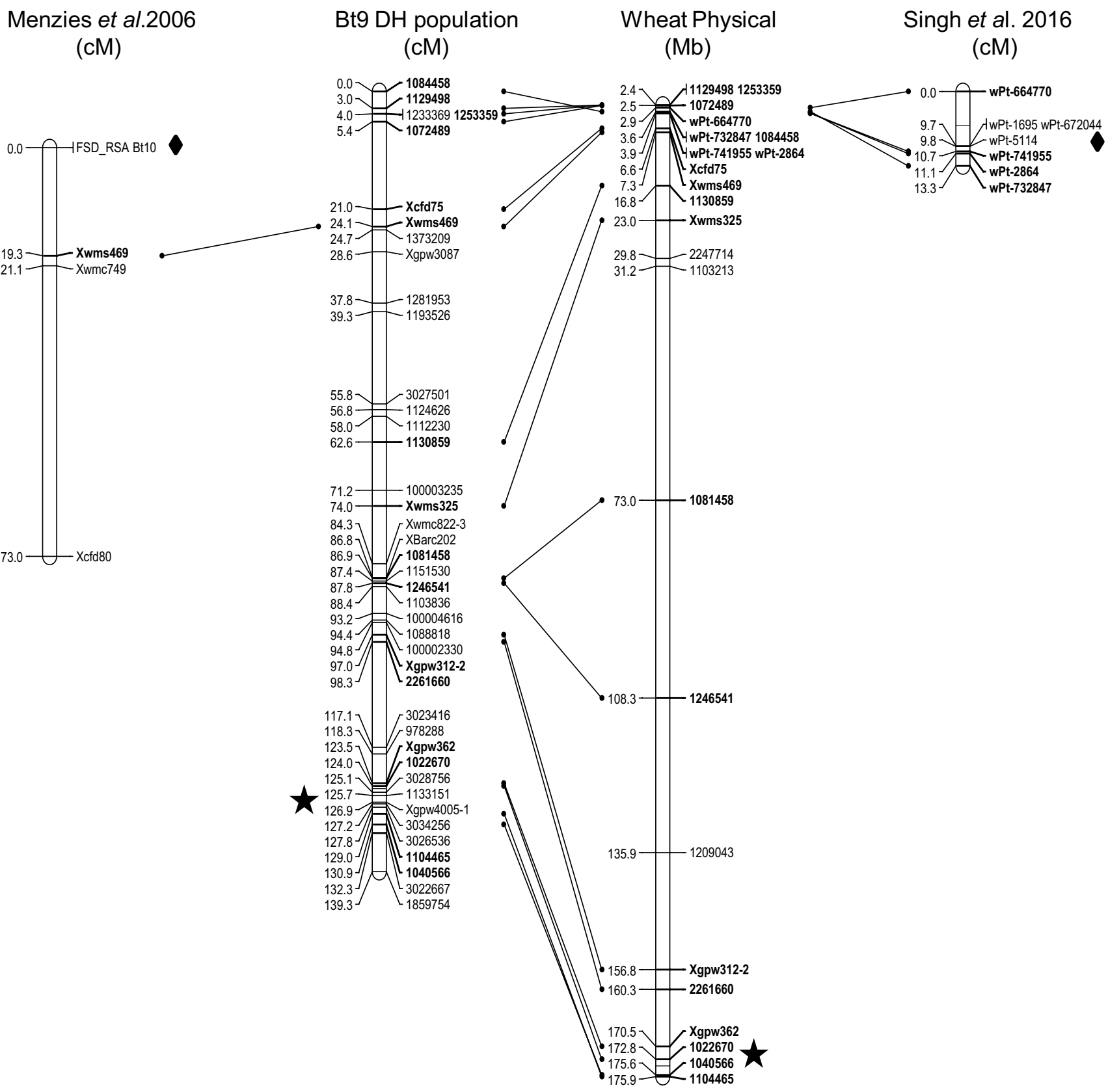

Fig. 4 Genetic and physical map of chromosome 6D of wheat, showing the position of the $B t 9$ region. The genetic map was created using the $88 \mathrm{DH}$ lines from the population PI $554099 \times c v$ Cortez, while the physical map was created based on the Triticum_aestivum. IWGSC1+popseq.31 genome assembly. On these two maps only one marker is shown per bin (unique positions). Markers with prefix

infection levels of DH lines under greenhouse and field conditions were similar, it was concluded that $B t 9$ proved effective under both field and greenhouse conditions.

The failure to detect the $B t 9$ QTL in the field screen in 2013 (Fd13) may be attributed to the late sowing in October 2012, which had an effect on the number of plants available for assessment as well as on the overall infection
Xgpw, Xwms, Xwmc, Xcfd or Xbarc are SSR markers, while markers without a prefix are DArTseq markers. The position of the Bt10 region is indicated by interpolation from two previous genetic maps developed by Menzies et al. (2006) and Singh et al. (2016). The Bt9 region is indicated by a star, while the $B t 10$ region is indicated by a square

level. Sowing into cooler soil conditions, as was the case in autumn 2012 compared to the sowing in autumn 2011, is known to increase infection levels (Reed 1928; Gaudet and Puchalski 1990), which was also observable in the present study, and may have reduced the effect of the $B t 9$ QTL in the field assessments of 2013. 
The high number of plants needed and the long time required to assess common bunt resistance reactions phenotypically render the availability of a molecular marker in close linkage to common bunt resistance genes a valuable tool for marker-assisted selection. Such markers present the possibility of pyramiding several resistance factors into a single wheat line, which may offer a valuable resistance source for organic and low-input agricultural systems. In the present linkage analysis, five SSR markers linked to $B t 9$ were identified, as well as a large number of SNP and PAV markers that could be developed into robust markers for $B t 9$ selection. In addition, these markers may be useful for future projects aimed at fine mapping the $B t 9$ QTL and subsequently identifying the causal gene behind the trait.

Author contribution statement The experiment was conceived by PMS, GB, AB and SKR. PMS and AB carried out the phenotypic evaluation. Genotyping with SSR markers as well as analysis of phenotypic data, map construction and QTL analysis was carried out by PMS and AMT, while AMT did the bioinformatics including comparison of genetic and physical maps. The manuscript was drafted by PMS, AMT and SKR, and corrected and approved by all authors.

Acknowledgements We kindly thank Nordic Seed A/S, Galten, Denmark for the provision of the DH populations used in the present study. Funding by the Danish Ministry of Food, Agriculture and Fisheries is gratefully acknowledged.

\section{Compliance with ethical standards}

Conflict of interest The authors declare that they have no conflict of interest.

Funding NaturErhvervstyrelsen: Bioteknologisk hvedeforædling til økologisk jordbrug (BioBreed), Grant Number 3304-FVFP09-B-017-1.

Open Access This article is distributed under the terms of the Creative Commons Attribution 4.0 International License (http:// creativecommons.org/licenses/by/4.0/), which permits unrestricted use, distribution, and reproduction in any medium, provided you give appropriate credit to the original author(s) and the source, provide a link to the Creative Commons license, and indicate if changes were made.

\section{References}

Akbari M, Wenzl P, Caig V, Carling J, Xia L, Yang S, Uszynski G, Mohler V, Lehmensiek A, Kuchel H, Hay- den MJ, Howes N, Sharp P, Vaughan P, Rathmell B, Huttner E, Kilian A (2006) Diversity arrays technology (DArT) for high-throughput profiling of the hexaploid wheat genome. Theor Appl Genet
113(8):1409-1420. doi:10.1007/s00122-006-0365-4; http:// www.springerlink.com/content/u30073810rx17ku3/

Babayants LT, Babayants OV, Baranovskaya VL, Dubinina LA (2006) Tilletia caries and resistance of wheat to this pathogen in Ukraine. Czech J Genet Plant Breed 42:33-36

Borgen A (2015) Purifying virulence races of common bunt (Tilletia caries) to identify resistance genes in wheat. Abstracts of the COBRA Final conference, 24-25th November 2015, Vingstedcenteret, Denmark. pp 32-34

Borgen A, Kristensen L (2003) Macroscopic leaf symptoms in wheat infected by Tilletia tritici. Zeitschrift für Pflanzenkrankheiten und Pflanzenschutz 110: 432-436

Brenchley R, Spannagl M, Pfeifer M, Barker GLA, D’Amore R, Allen AM, McKenzie N, Kramer M, Kerhornou A, Bolser D, Kay S, Waite D, Trick M, Bancroft I, Gu Y, Huo N, Luo MC, Sehgal S, Gill B, Kianian S, Anderson O, Kersey P, Dvorak J, McCombie WR, Hall A, Mayer KFX, Edwards KJ, Bevan MW, Hall N (2012) Analysis of the bread wheat genome using whole-genome shotgun sequencing. Nature 491(7426):705710. doi:10.1038/nature 11650

Bressman EN (1931) Varietal resistance, physiologic specialisation, and inheritance studies in bunt of wheat. Agric Exp Station Oregon State Agric Coll Station Bulletin 281:1-44

Choulet F, Alberti A, Theil S, Glover N, Barbe V, Daron J, Pingault L, Sourdille P, Couloux A, Paux E, Leroy P, Mangenot S, Guilhot N, Le Gouis J, Balfourier F, Alaux M, Jamilloux V, Poulain J, Durand C, Bellec A, Gaspin C, Safar J, Dolezel J, Rogers J, Vandepoele K, Aury JM, Mayer K, Berges H, Quesneville H, Wincker P, Feuillet C (2014) Structural and functional partitioning of bread wheat chromosome 3B. Science 345:1249721

Ciucã M (2011) A preliminary report on the identification of SSR markers for bunt (Tilletia sp.) resistance in wheat. Czech J Genet Plant Breed 47:S142-S145

Cruz VMV, Kilian A, Dierig DA (2013) Development of DArT marker platforms and genetic diversity assessment of the U.S. collection of the new oilseed crop Lesquerella and related species. PLoS One 8(5):e64062. doi:10.1371/journal.pone.0064062

Demeke T, Laroche A, Gaudet D (1996) A DNA marker for the Bt-10 common bunt resistance gene in wheat. Genome 39(1):51-55. doi:10.1139/g96-007; http://www.nrc.ca/cgi-bin/cisti/journals/ rp/rp2_abst_e?gen_g96-007_39_ns_nf_gen39-96

Dumalasová V, Simmonds J, Bartoš P, Snape J (2012) Location of genes for common bunt resistance in the european winter wheat cv. Trintella. Euphytica 186:257-264. doi:10.1007/ s10681-012-0671-7

Eurostat (2014) Area under organic farming (ts-dpc440). Tech. rep., European Commission, http://epp.eurostat.ec.europa.eu/tgm/ table.do? tab $=$ table \&plugin $=1 \&$ language $=$ en $\&$ pcode $=$ tsdpc 440 . Accessed 21 Feb 2017

Fofana B, Humphreys DG, Cloutier S, McCartney CA, Somers DJ (2008) Mapping quantitative trait loci con- trolling common bunt resistance in a doubled haploid population derived from the spring wheat cross RL4452 × AC Domain. Molecular Breeding 21(3):317-325. doi:10.1007/s11032-007-9131-9; http://www. springerlink.com/content/p62g875422q7q1jt/export-citation/

Galaev AV, Babayants LT, Sivolap YM (2006) DNA-markers for resistance to common bunt transferred from aegilops cylindrica host to hexaploid wheat. Czech J Genet Plant Breed 42:62-65

Gaudet DA, Puchalski BJ (1990) Influence of planting dates on the aggressiveness of common bunt races (Tilletia tritici and Tilletia laevis) to Canadian spring wheat cultivars. Can J Plant Pathol 12(2):204-208

Goates BJ (1996) Common bunt and dwarf bunt. In: Wilcoxson RD, Saari EE (eds) Bunt and smut disease of wheat: concepts and methods of disease management, CIM-MYT, Mexico, D.F 
Goates BJ (2012) Identification of new pathogenic races of common bunt and dwarf bunt fungi, and evaluation of known races using an expanded set of differential wheat lines. Plant Dis 96:361369. doi:10.1094/PDIS-04-11-0339

Goates BJ, Bockelman HE (2012) Identification of new sources of high levels of resistance to dwarf bunt and common bunt among winter wheat landraces in the USDA-ARS national small grains collection. Crop Science 52:2595-2605. https://www.crops.org/ publications/cs/abstracts/52/6/2595

Gupta PK (2007) Cytogenetics. Rastogi Publications, Meerut

Harlan JR (1950) Collection of crop plants in Turkey, 1948. Agron J 42:258-259. https://www.agronomy.org/publications/aj/ abstracts/42/5/258

Hoffmann JA (1971) Control of common and dwarf bunt of wheat by seed treatment with thiabendazole. Phytopathology 61:1071-1074

Hoffmann JA, Waldher JT (1981) Chemical seed treatments for controlling seedborne and soilborne common bunt of wheat. Plant Dis 65(256-259): 1

Jia J, Zhao S, Kong X, Li Y, Zhao G, He W, Appels R, Pfeifer M, Tao Y, Zhang X, Jing R, Zhang C, Ma Y, Gao L, Gao C, Spannagl M, Mayer KFX, Li D, Pan S, Zheng F, Hu Q, Xia X, Li J, Liang Q, Chen J, Wicker T, Gou C, Kuang H, He G, Luo Y, Keller B, Xia Q, Lu P, Wang J, Zou H, Zhang R, Xu J, Gao J, Middleton C, Quan Z, Liu G, Wang J, Yang H, Liu X, He Z, Mao L, Wang J (2013) Aegilops tauschii draft genome sequence reveals a gene repertoire for wheat adaptation. Nature 496:91-95. doi:10.1038/ nature 12028

Kloppers FJ, Pretorius ZA (1997) Effects of combinations amongst genes Lr13, Lr14 and Lr37 on components of resistance in wheat to leaf rust. Plant Pathol 46:737-750

Knox RE, Campbell HL, Depauw RM, Gaudet D, Puchalski B, Clarke FC (2013) DNA markers for resistance to com- mon bunt in McKenzie wheat. Can J Plant Pathol 3:328-337. doi:10.1080/07 060661.2013.763292; http://www.tandfonline.com/doi/abs/10.10 80/07060661.2013.763292

Laroche A, Demeke T, Gaudet DA, Puchalski B, Frick M, McKenzie R (2000) Development of a PCR marker for rapid identification of the Bt-10 gene for common bunt resistance in wheat. Genome 43:217-223

Li HH et al (2007) A modified algorithm for the improvement of composite interval mapping. Genetics 175:361-374

Li HH et al (2015) A high density GBS map of bread wheat and its application for dissecting complex disease resistance traits. BMC Genomics 16:216. doi:10.1186/s12864-015-1424-5

Long DL, Leonard KJ, Roberts JJ (1998) Virulence and diversity of wheat leaf rust in the United States in 1993 to 1995. Plant Dis 82:1391-1400

Mamluk OF (1998) Bunts and smuts of wheat in North Africa and the near east. Euphytica 100:45-50. doi:10.1023/A:1018343603827

Martynov S, Dobrotvorskaya TV (2003) Genealogical analysis of Russian and Ukrainian winter wheat resistant to common bunt.
Annu Wheat Newslett 49:127-133. http://wheat.pw.usda.gov/ ggpages/awn/49/AWN\%20PDFs/AWN_VOL49_4.pdf. Accessed 29 June 2014

McIntosh R, Hart G, Devos K, Gale M, Rogers W (1998) Catalogue of gene symbols for wheat. http://wheat.pw.usda.gov/ggpages/ wgc/98/. Accessed 29 June 2014

Meng L et al (2015) QTL IciMapping: Integrated software for genetic linkage map construction and quantitative trait locus mapping in biparental populations. Crop J 3:269-283

Menzies JG, Knox RE, Popovic Z, Procunier JD (2006) Common bunt resistance gene Bt10 located on wheat chromosome 6D. Can J Plant Sci 86:1409-1412

Orabi J, Jahoor A, Backes G (2014) Changes in allelic frequency over time in European bread wheat (Triticum aestivum L.) varieties revealed using DArT and SSR markers. Euphytica 197(3):447462, doi:10.1007/s10681-014-1080-x

Reed GM (1928) Physiologic races of bunt of wheat. American Journal of Botany 15:157-170. http://www.jstor.org/stable/24356602

Rubiales D, Moral A, Martin A (2001) Chromosome location of resistance to septoria leaf blotch and common bunt in wheat-barley addition lines. Euphytica 122:369-372

Schmidt J, Morris R, Johnson V (1969) Monosomic analysis for bunt resistance in derivatives of Turkey and Oro wheats. Crop Sci 9:286-288

Sears ER, Schaller CW, Briggs FN (1960) Identification of the chromosome carrying the Martin gene of resistance of wheat to bunt. Can J Cytol 2:262-267

Singh A, Knox RE, DePauw RM, Singh AK, Cuthbert RD, Kumar S, Campbell HL (2016) Genetic mapping of common bunt resistance and plant height QTL in wheat. Theor Appl Genet 129:243-256

van Slageren MW (1994) Wild wheats: a monograph of Aegilops L. and Amblyopyrum (Jaub. and Spach) Eig (Poaceae). vol 7 Wageningen Agricultural University Press, Wageningen, pp 1-512

Van Ooijen JW (2006) JoinMap 4, software for calculation of genetic linkage maps in experimental populations. Kyazma BV, Wageningen

Voorrips RE (2002) MapChart: software for the graphical presentation of linkage maps and QTLs. J Hered 93(1):77-78

Wang S, Knox RE, DePauw RM, Clarke FR, Clarke JM, Thomas JB (2009) Markers to a common bunt resistance gene derived from 'Blizzard' wheat (Triticum aestivum L.) and mapped to chromosome arm 1BS. Theor Appl Genet 119:541-553. doi:10.1007/ s00122-009-1063-9

Waud JL, Metzger RJ (1970) Inheritance of a new factor (Bt8) for resistance to common bunt in wheat. Crop Sci 10:703-704

Wilkinson P, Winfield M, Barker G, Allen A, Burridge A, Coghill J, Edwards K (2012) Cerealsdb 2.0: an integrated resource for plant breeders and scientists. BMC Bioinformatics 13(1):219, doi:10.1186/1471-2105-13-219; http://www.biomedcentral. com/1471-2105/13/219 